\title{
Empreendedorismo e Sustentabilidade: Uma Visão Psicológica
}

\author{
Patricia Pereira de Sousa Timóteo ${ }^{1}$; Theóphilo Michel Álvares Cabral Beserra ${ }^{2}$
}

\begin{abstract}
Resumo: o presente trabalho teve por finalidade, discutir a cultura organizacional predatória, vigente nas empresas atuais. A visão holística do fenômeno do empreendedorismo, considera as empresas como "sistemas abertos", passíveis de modificação pela ação externa. Adotou-se como referencial teórico a Psicologia Comportamental e o Pensamento Sistêmico. A metodologia utilizada foi a analítico-descritiva, baseada na pesquisa de cunho bibliográfico e documental com apreciação qualitativa dos dados. Procurou-se observar a cultura organizacional através da educação - ação cognitiva direcionada, recorrendo à Psicologia, como suporte para desconstruir os padrões mentais existentes. Tal estratégia permitiu reconstruir novos padrões, baseados nos preceitos da sustentabilidade, refazendo a conexão natural que o homem possui com a natureza a que pertencemos. Dessa forma, acredita-se conseguir o equilíbrio psíquico que permite o sadio desenvolvimento das empresas, e da sociedade de uma maneira geral.
\end{abstract}

Palavras-Chave: Empreendedorismo; Sustentabilidade; Psicologia; Cultura Organizacional; Educação.

\section{Entrepreneurship and Sustainability: A Psychological Perspective}

\begin{abstract}
The purpose of this study was to discuss the predatory organizational culture in current companies. The holistic view of the phenomenon of entrepreneurship considers companies as "open systems", which can be modified by external action. Behavioral Psychology and Systemic Thinking were adopted as theoretical references. The methodology used was analytical-descriptive, based on bibliographic and documentary research with qualitative appreciation of the data. We sought to observe organizational culture through education - directed cognitive action, using Psychology as a support to deconstruct existing mental patterns. This strategy allowed us to reconstruct new patterns, based on the precepts of sustainability, reworking the natural connection that man has with the nature to which we belong. In this way, it is believed to achieve the psychic balance that allows the sound development of companies and society in general.
\end{abstract}

Keywords: Entrepreneurship; Sustainability; Psychology; Organizational culture; Education.

\footnotetext{
${ }^{1}$ Mestranda em ciências da Educação. Tem experiência na área de Administração e Administração de Recursos Humanos, como docente em Coaching, Empreendedorismo, Gestão de Pessoas, Liderança e Recrutamento e Seleção. Lecionando e coordenando projetos complementares à atividade de ensino, na Universidade (UVA - IDJ). Possui graduação em Direito pela Faculdade Paraíso do Ceará. É pós - graduada em MBA Internacional em Liderança. E pós - graduada em Docência do Ensino Superior. Com formação Coaching e Programação Neurolinguística (PNL) Master e Pratictioner, e Liderança Coaching. E-mail: ppstimoteo@ hotmail.com;

${ }^{2}$ Mestre em Geografia pela Universidade Federal do Ceará, Especialista em Geografia e Meio Ambiente pela Universidade Regional do Cariri, licenciado em geografia pela Universidade Regional do Cariri. Atualmente é membro do Conselho Municipal de Defesa do Meio Ambiente de Juazeiro do Norte - Ceará - COMDEMA, membro do Comitê Institucional de Avaliação do Programa de Bolsas de Iniciação Científica e Tecnológica do Instituto CENTEC, Conselheiro do Eixo Tecnológico Ambiente e Saúde da Faculdade de Tecnologia CENTEC, FATECCARIRI, membro do Núcleo Docente Estruturante do Eixo Tecnológico Ambiente e Saúde e representante docente eleito para o Conselho de Administração do Instituto CENTEC junto a Secretaria da Ciência, Tecnologia e Educação Superior do Estado do Ceará - SECITECE. Professor do eixo tecnológico ambiente e saúde. E-mail: mic.beserra@hotmail.com.
} 
Id on Line Revista Multidisciplinar e de Psicologia

Id on Line Multidisciplinary and Psycology Journal

\section{Introdução}

Empreendedorismo é uma atividade intrínseca ao ser humano. Que vive continuamente empreendendo algo, e conduzindo os avanços das civilizações. A figura do empreendedor se mostra presente em todos os momentos em que se requer uma inovação frente àquilo que já é conhecido.

"O empreendedor é aquele que destrói a ordem econômica existente através da introdução de novos produtos e serviços, pela criação de novas formas de organização, ou pela exploração de novos recursos e materiais", para Joseph Schumpeter (1961). Tal citação destaca bem o papel do empreendedor nos cenários de mudanças enfrentados historicamente. Papel decisivo nesses momentos. Segundo o autor brasileiro, José Dornelas (2001), “empreendedor é aquele que faz acontecer, se antecipa aos fatos e tem uma visão futura da organização".

Para a psicologia, viver em harmonia com o meio ambiente é uma tendência natural do ser humano. Já que somos parte dele, e interdependentes com outras espécies animais e vegetais, num ecossistema em perfeito equilíbrio. De forma interdisciplinar, e em consonância com outras disciplinas como a sociologia e antropologia, enxerga-se essa conexão existente.

Tal ligação se dissolve com a vida urbana, dando a sensação de não pertencimento à natureza a sua volta. A hiperurbanização afasta o homem de suas raízes. Levando-o a desenvolver sistemas de produção baseados na exploração predatória dos recursos naturais e a consequente degradação de seu próprio habitat .

Sendo pois, tendência natural do homem empreender, bem como estar em equilíbrio com a natureza em que vive, sua harmonia estará em buscar as suas raízes. Promovendo um Empreender Sustentável nas organizações, recorrendo à "Psicologia" como instrumento de apoio e orientação no alcance de seus propósitos.

A metodologia utilizada é a analítico-descritiva, a partir da pesquisa de cunho bibliográfico e documental. Buscando explorar a produção científica de renomados autores a respeito do tema abordado. Numa perspectiva qualitativa de análise de dados. Considerando a abordagem da Psicologia Comportamental e o Pensamento Sistêmico.

Buscando atuar sobre a cultura organizacional, considerando essa, um fator administrável. Inicia-se com o estudo do fenômeno do empreendedorismo na perspectiva 
Id on Line Revista Multidisciplinar e de Psicologia

Id on Line Multidisciplinary and Psycology Journal

psicológica. Em seguida explora-se a relação do homem com meio ambiente aos olhos da psicologia. Compreendendo a sustentabilidade como um problema organizacional, passível da atuação humana.

\section{Empreendedorismo e Psicologia}

Nos estudos sobre empreendedorismo encontramos o conceito elucidativo de José Dornelas (2001), sobre a figura do empreendedor: "É aquele que faz acontecer, se antecipa aos fatos e tem uma visão futura da organização”. Buscando compreender os mecanismos que envolvem esse fenômeno, e possibilitam sua intervenção no mundo empresarial, recorre-se à Psicologia dando embasamento a essas descobertas.

Observando a evolução histórica do homem na Terra, o constante aperfeiçoamento de seu modo de viver, constata-se que o empreendedorismo decorre da própria natureza humana. A capacidade do homem de racionalizar sobre suas necessidades, lhe capacita para buscar meios de atendê-las. Encontrando novas formas de fazê-lo. E isso é inovação empreendedora!

Para Ferreira (1999), empreender é um ato deliberado, intencional. E na visão psicológica holística, cada homem comporta dentro de si o impulso empreendedor. Decorrente da própria natureza. Portanto, a força empreendedora provém da energia dinâmica implícita no universo. Promovendo um "efeito sinergético", que potencializado, gera a capacidade criativa no homem.

Através da Teoria Comportamental, o ambiente organizacional e a Psicologia se aliaram, desenvolvendo a Psicologia Organizacional. Agindo nas relações de trabalho dentro das instituições produtivas. Atuando na cultura organizacional, percepções culturais de uma organização. Busca-se uma intervenção planejada na cultura organizacional, considerando essa, um fator administrável, como defendido por Pettigrew (1989).

Segundo a Teoria dos Sistemas foi proposta por Bertalanffy, no final da década de 1930, partindo da concepção de que a realidade é feita de sistemas, de elementos interdependentes que precisam ser analisados nas suas inter-relações, com uma visão interdisciplinar e holística (MAXIMIANO, 2000). 
Perante essa teoria, as empresas são consideradas "sistemas abertos". E portanto, são suscetíveis a ações externas. Mutáveis e adaptáveis. Chiavenato (1994) destaca que o enfoque sistêmico trata-se de uma "visão integrada" que nos impele a ir além dos aspectos internos para realizar planejamentos estratégicos mais elaborados.

\section{Sustentabilidade e Psicologia}

Mesmo diante de intensa exploração temática em torno da sustentabilidade, pouco temse avançado nesse sentido dentro das organizações. Levando-nos a recorrer aos conhecimentos da Psicologia para compreender os motivos dessa situação. O que move tais comportamentos, como modificar esse cenário.

Segundo Marco Aurélio Bilibio (2013), defensor da Ecopsicologia explica didaticamente: "existe na raiz da nossa psique uma conexão básica com a natureza. A repressão dessa conexão na sociedade industrial nos fez perder o senso de pertencimento à natureza. A hiperurbanização do nosso modo de viver torna esse senso cada vez mais débil, gerando algo que poderíamos definir de psique urbana”.

Essa chamada "psique urbana", é que transmite a falsa sensação de separação entre o homem e a natureza. A ideia de não pertencimento ao meio ambiente natural. E a criação cidades, metrópoles artificiais desenvolvidas pelo homem, promovem a naturalização da vida urbana, reforçam essa impressão. E aliado à necessidade de produção em larga escala, derivada do sistema capitalista; conduz a ação antrópica exploratória, destrutiva dos recursos naturais.

Segundo Leonnardo Boff (2010), somos parte da natureza, e sofremos com qualquer dano causado a ela. Inevitavelmente, refletirá em nós. Ao longo de seus estudos sociológicos e multidisciplinares, encontramos apoio quanto às relação do homem com o meio ambiente. Ele afirma sermos uma porção do todo, que é a natureza. Pertencemos a ela. Dependemos dela.

Para a Psicologia as patologias psicológicas observadas atualmente, também são fruto do afastamento homem de suas raízes. E somente quando modificamos nossa postura com relação à natureza, enxergando a sua importância em nossas vidas encontraremos o equilíbrio psíquico que desejamos. 
Assim, o homem moderno precisa encontrar uma forma de empreender, produzindo sustentavelmente. Resguardando seu equilíbrio pessoal e ecológico (de acordo com suas raízes), e como forma de perpetuar o sistema produtivo vigente. Garantindo a sua sobrevivência atual no mercado e para as futuras gerações.

\section{Considerações Finais}

Através dos estudos levantados, defende-se a ideia de que o homem pertence à natureza. É parte integrante dela. E portanto, é interdependente desse ecossistema. Vive em simbiose com as outras espécies de vida na Terra. E assim, sofre com todo desequilíbrio que provoca ao planeta. De diversas formas, acaba sendo atingido.

No campo psicológico, considera-se que o ser humano possui em sua "psique" uma conexão básica com a natureza. Porém a vida moderna, urbana, artificialmente construída; nos afastada dela. Nos dando a sensação de não pertencimento ao meio ambiente. Provocando a desvinculação (aparente) de nossas ações predatórias, das consequências geradas em nós mesmos.

No entanto, sustentabilidade é um problema social e também organizacional. Considerando as empresas como instituições que replicam a cultura social vigente. E a recriam na figura da Cultura Organizacional. Um fator administrável, visto como um "sistema aberto" passível de modificação perante a ação humana.

Dessa forma, mediante a ação humana proposital, a conquista se aproxima. O empreender sustentável passa a ser possível, alcançável. Apontado como solução para a economia, o meio ambiente, e para a promoção do bem estar psíquico dos homens na atualidade.

Porém só se torna viável, diante da intervenção cognitiva direcionada dentro das empresas. Focada em modificar a cultura organizacional existente, para uma mais consciente. Promovendo uma educação complementar, voltada para a mudança dos padrões mentais vigentes no grupo.

Somente através da educação pode-se promover o desenvolvimento de uma nova cultura organizacional. Focada em atender as necessidades humanas frente ao dinamismo do universo, 
enxergando a sustentabilidade como uma das necessidades do homem. Um dos quesitos para a conquista do bem comum. Utilizando-se da Psicologia como aliada nesse processo. Como mecanismo de suporte e orientação para construção desse saber coletivo, institucionalizado, capaz de mudar atitudes no ambiente empresarial - a cultura organizacional.

\section{Referências}

BILIBIO, E. Os momentos constitutivos do Cuidado e o Dasein como ser de relações. ethic@, Florianópolis, v. 12, n. 2, p. 272-288, dez. 2013.

BOFF, Leonardo. Ecologia Social. Disponível em: https://www.youtube.com/watch?v=LOUNIUbXNgk acesso em: 23 out 2015.

CHIAVENATO, I. Iniciação a Administração Geral. 2º ed. São Paulo: Makron Books, 1994. $80 \mathrm{p}$.

DORNELAS, José Carlos Assis. Empreendedorismo: transformando idéias em negócios. Editora Campus, 2001.

FERREIRA, A.B.H. Novo Aurélio - Dicionário da Língua Portuguesa. 3. ed. Rio de Janeiro: Nova Fronteira, 1999.

MAXIMINIANO, A. C. A. Introdução à administração: da revolução urbana a revolução digital. $3^{\circ}$ ed. São Paulo: Atlas, 2002. 521 p.

PETTIGREW, A. M. A cultura das organizações é administrável? In: Maria Tereza Fleury e Rosa Maria Fischer (org.). Cultura e poder nas organizações. São Paulo: Atlas, 1989. 227. p.145-153.

SCHUMPETER, J. A. (1961). Teoria do desenvolvimento econômico. (L. Schlaepfer, Trad.). Rio de Janeiro: Fundo de Cultura. (Obra original publicada em 1911).

Como citar este artigo (Formato ABNT):

TIMÓTEO, P.P.S.; BESERRA, T.M.A.C. Empreendedorismo e sustentabilidade: uma visão Psicológica. Id on Line Revista Multidisciplinar e de Psicologia, Nov-Dez. de 2016, vol.10, n.32, p. 173-178. ISSN: 1981-1179.

Recebido: $17 / 09 / 2016$

Aceito: 22/09/2016 